\title{
The effect of list difficulty on item difficulty using the method of stimulated recall'
}

EDWARD A. BILODEAU AND MICHAEL A. MURPHY, DEPARTMENT OF PSYCHOLOGY, TULANE UNIVERSITY, New Orleans, La. 70118

Ten words found difficult to recall in previous studies when they appeared in mixed lists (easy and difficult words together) and five words easy to recall in the same situation were redistributed within lists which contained either all difficult words, all easy words, or mixtures of easy and difficult words. Two minutes after study, Stimulated Recall was requested. No difference in recall of an item was attributable to list mixture. The results suggest ease or difficulty of item recall was solely a function of the stimulus in recall.

Bilodeau \& Blick (1965) used the Method of Stimulated Recall and a 2 min retention interval to identify common words whose proportion of correct recoveries ranged from $p=.10$ to $p=1.00$. Bilodeau \& Howell (in press), in an extensive associative analysis of these words, showed their properties and why some are more easily remembered than others. The present study asks if recall of a word is a function of the retrieval value of neighboring words. If the context within a list plays a role, the associative analysis will have to be modified.

Table 1 shows the Easy and Difficult lists used here. "Night," for example, was used as Item 1 of an Easy list and "dark" was the stimulus. In the Method of Stimulated Recall, $S$ is typically required to study the list for $20 \mathrm{sec} ; 120 \mathrm{sec}$ of vowel cancellation follows training, and then a test period for recall in the presence of the stimuli terminates the session. In the present example, "dark" would appear as a stimulus on the test page. ("Dark" does not appear on the training page; this is not a paired-associate procedure.)

Bilodeau \& Blick (1965) found "night" to be an Easy word (i.e., well recalled) when it is a member of a Mixed list. Their data tell us nothing about the possible behavior of "night" when all the words of the list are Easy. If an Easy word were assigned to a list composed entirely of Easy words and if a Difficult word were assigned to a list composed entirely of Difficult words, the

Table 1

Lists of Words for Four Levels of Difficulty

Easy-Difficult Lists and Mixes, Set $1^{\text {a }}$

\begin{tabular}{cllll} 
Item & 5E & 5D & 3E2D & 3D2E \\
\hline 1 & night & foot & night & foot \\
2 & scared & note & note & scared \\
3 & red & rock & red & rock \\
4 & finger & mouse & mouse & finger \\
5 & sea & food & sea & food \\
\hline
\end{tabular}

${ }^{a}$ The stimuli for the four lists above are, respectively: dark, afraid, yellow, hand, ocean; head, music, hard, cheese, table; dark, music, yellow, cheese, ocean; head, afraid, hard, hand, table.

Easy-Difficult Lists and Mixes, Set $2^{b}$

\begin{tabular}{lllll}
\cline { 2 - 4 } Item & SE & SD & 3E2D & 3D2E \\
\hline 1 & sea & snow & sea & snow \\
2 & finger & lamp & lamp & finger \\
3 & red & loafing & red & loafing \\
4 & scared & school & school & scared \\
5 & night & apple & night & apple \\
\hline
\end{tabular}

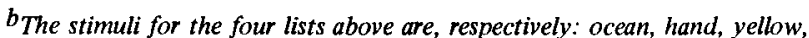
afraid, dark; cold, light, working, high, blossom; ocean, light, yellow, high, dark; cold, hand, working, afraid, blossom.
Table 2

Proportion of Items Recalled for Each of Two Sets of Lists over Four Levels of Difficulty

\begin{tabular}{|c|c|c|c|c|c|c|c|c|}
\hline \multirow[b]{2}{*}{ Item Order } & \multicolumn{2}{|c|}{ Easy (E) } & \multicolumn{2}{|c|}{ Difficult (D) } & \multicolumn{2}{|c|}{ 3E2D } & \multicolumn{2}{|c|}{ 3D2E } \\
\hline & 1 & 2 & 1 & 2 & 1 & 2 & 1. & 2 \\
\hline 1 & .81 & .90 & .57 & .52 & .86 & .95 & .43 & .71 \\
\hline 2 & .81 & .62 & .48 & .33 & .62 & .29 & .71 & .71 \\
\hline 3 & .62 & .67 & .38 & .33 & .67 & .62 & .38 & .38 \\
\hline 4 & .57 & .86 & .67 & .19 & .71 & .14 & .48 & .86 \\
\hline 5 & .86 & .71 & .33 & .38 & .81 & .67 & .29 & .33 \\
\hline Mean & .73 & .75 & .49 & .35 & .73 & .53 & .46 & .60 \\
\hline Grand Mean & \multicolumn{2}{|c|}{.74} & \multicolumn{2}{|c|}{.42} & \multicolumn{2}{|c|}{.63} & \multicolumn{2}{|c|}{.53} \\
\hline
\end{tabular}

outcome is not certain. Indeed, at least two alternate predictions suggest themselves (Lachman \& Tuttle, 1965). (1) If the process of storage controls the ease or difficulty of a word, the words found easy in a Mixed list would become easier still in an all Easy list while words found difficult in a Mixed list would become even more so in an all Difficult list. (2) If a process of construction during recall controls the ease or difficulty of a word, the stimulus might so strongly control the recall of each item that list context would have no effect and ease or difficulty of an item would not covary at all. The experiment below will help clarify the relative contribution made to the explanation of recall by the storage and construction hypotheses.

Subjects and Design. The eight lists shown in Table 1 were assigned to 168 Air Force basic trainees, 21 Ss per list. Ten especially difficult and five easy words were available for assignment to lists. This made it necessary for us to repeat the easy words in Set 2 . Either set bears on the hypothesis. Inspection of Table 1 will reveal how Easy (E) and Difficult (D) items were assigned positions within the experimental groups. In Group 3E2D, the three Easy items take positions 1, 3, and 5; and two Difficult items take positions 2 and 4. In 3D2E, the three Difficult items take positions 1,3 , and 5 and the two Easy items take positions 2 and 4.

Procedure. The items were presented in a four page booklet with the following events obtaining:

\begin{tabular}{ccc} 
Training & Interp. Act. & Recalling \\
\hline Page A, Page B & Vowel Cancel & Stimulated Recall \\
20 sec each & 120 sec & Page B, 120 sec \\
\hline
\end{tabular}

One of the lists of Table 1 was always on Page B and the stimuli were always on the Stimulated Recall page. Page $A$ words were associatively neutral with respect to Page B words and their stimuli. Page A simply functions as another list added to S's load. S did not know that $E$ would request recall from Page A or B. The instructions during Training on Lists A and B simply directed him to "study the words below." For further detail on precedures, outcomes, and explanations of the experiments in this series a review by Bilodeau (1966) should be consulted.

Results and Discussion. The proportions of correct recall for the two sets of lists over four levels of difficulty are given in Table 2. The four means yield the relation $5 E>3 E 2 D>3 D 2 E>$ 5D after adding over sets. Thus, the greater the number of Easy words in the list, the greater the value of correct recall. The range of means $(.74-.42)$ is .32 , a generous difference which shows the power of the Easy-Difficult phenomenon.

Two methods for assessing the effect of ease and difficulty (which inspection suggested was a simple additive rule) were evaluated.

(1) Control data used to estimate experimental data: Since the mean of $5 \mathrm{E}=.74$, then $1 \mathrm{E}=.148(.74$ divided by 5$)$; and since $5 \mathrm{D}$ $=.42$, then $1 \mathrm{D}=.084$ (.42 divided by 5$)$. Therefore, 3E2D 
becomes $3 \times .148+2 \times .084$ or $.61 ; 3 \mathrm{D} 2 \mathrm{E}$ becomes $3 \times .084+2 \times$ .148 or .55 . The estimated grand mean values for the experimental groups are within .02 of the observed values $(.63, .53)$ and indicate a good fit.

(2) Control words collected for artificial mixed lists: Every word in a Mixed list also appeared in an Easy and a Difficult list. The words in Easy and Difficult lists were reassembled to make artificial mixes of 3E2D or 3D2E. This method has the advantage of holding words constant from comparison to comparison. The mean of the artificial Mixed lists was .581, the very same value obtained from the Mixed lists.

The two methods above are related, and both indicate an Easy item remains easy and a Difficult item remains difficult whether the list is heterogeneous or homogeneous. This outcome is consistent with the idea that stimulated recall regulates construction with such dominance that other variables such as list mix ture at acquisition are overridden. The results of the study have a practical advantage. E need not follow an elaborate rule for word mixing within lists in future experiments with these or similar words. The boundary conditions are not known and the results should not be generalized too far from the common words and mixes used here.

\section{REFERENCES}

BLLODEAU, E. A. In E. A. Bilodeau (Ed.), Acquisition of skill. New York: Academic Press, 1966. Pp. 333-345.

BILODEAU, E. A., \& BLICK, K. A. Courses of misrecall over long-term retention intervals as related to strength of pre-experimental habits of word association. Psychol. Rep., 1965, 16, 1173-1 192.

BILODEAU, E. A., \& HOWELL, D. C. Association rules in the prediction of recall from free association matrices, Psychol. Bull., in press.

LACHMAN, R., \& TUTTLE, A. V. Approximations to English (ae) and short-term memory: construction or storage? J. exp. Psychol., 1965, 70 , 386-393.

1. This work was supported by Contract Nonr-475 (10) between Tulane University and the Office of Naval Research. 